\title{
РОЛЬ ГРАЖДАНСКОГО ОБЩЕСТВА В ДОСТИЖЕНИИ ЦЕЛЕЙ УСТОЙЧИВОГО РАЗВИТИЯ
}

\begin{abstract}
Фируза Хамдамова, доктор философии по юридическим наукам (PhD), заведующчий отделом гражданско-правовых и международно-правовых наук, а также международных организаций Института государства и права Узбекистана при Академии наук Узбекистана
\end{abstract}

DOI: https://doi.org/10.31435/rsglobal_conf/25052021/7563

Abstract. The article is devoted to the role of civil society in achieving the SDGs. The author notes that civil society institutions can play the role of initiators of social transformations, consultants, communicators, monitors and tools for strengthening partnerships both at the national and global levels, in the process of achieving the SDGs. At the same time, the article emphasizes the still insufficient level of civil society involvement in the achievement of the SDGs. The author provides an overview of the best practices in this area and makes proposals for activating civil society in the implementation of the SDGs.

The goal is to determine the role and functions of civil society in achieving the SDGs, identify the main areas of activity, develop recommendations for enhancing the role of civil society in achieving the SDGs.

Research methods - analysis of legal documents, review of best practices.

Research results. - Civil society is a key partner in achieving all 17 sustainable development goals, but is not sufficiently involved in the processes of achieving the SDGs;

- New forms of cooperation and interaction with civil society institutions should be introduced for their active involvement in the achievement of the SDGs;

Conclusions. It is necessary to ensure the involvement of civil society institutions in all stages of the implementation of the SDGs - from the development of national action plans for achieving the SDGs to reporting. At the same time, it is important to strengthen the interaction not only between the state and the institutions of civil society, but the interaction between the institutions of civil society themselves, including through the creation of their coalitions.

Keywords: civil society, sustainable development goals, voluntary national reviews, voluntary citizen reviews, SDG youth ambassadors, national sustainable development goals and targets.

Введение. Цели в области устойчивого развития (далее ЦУР) охватывают социальные, экологические и экономические аспекты жизни общества и государства. 17 ЦУР до 2030 года, это сформулированные ООН глобальные проблемы человечества и пути их решения.

Сегодня вопросы достижения этих целей, поиск путей и решений для устойчивого развития являются предметом широких дискуссий среди политиков, экспертов, ученых, исследователей и представителей гражданского общества, как на национальном, так и на международном уровне. Достижение ЦУР требует усилий и инвестиций как от государства, так и от частного сектора, а также институтов гражданского общества.

Гражданское общество изначально было вовлечено в разработку ЦУР. Разработка и принятие ЦУР яаляются результатом долгого консультативного процесса между ООН, государствами и глобальным гражданским обществом. Сегодня гражданское общество ключевой партнер государства в достижении ЦУР. Теоретически и практически бесспорно то, что гражданское общество и государство - две стороны одной медали, от взаимодействия которых, их известного противостояния, взаимопроникновения и взаимоконтроля зависят общественная стабильность, прогрессивные изменения, устойчивое развитие. ${ }^{1}$

Особенно важна роль гражданского общества в достижении социальных ЦУР, так как т.н. «третий сектор» сегодня основан на гражданских инициативах местных сообществ преимущественно в области образования, науки, здравоохранения, экологии, социальной защиты, то есть в социальной сфере.

1. Необходимость вовлечения гражданского общества в достижение ЦУР

О значимости гражданского общества в решении глобальных проблем свидетельствуют масштаб усилий, принимаемых на уровне ООН. Деятельность ООН в сфере поддержки гражданского пространства, вращается вокруг трех принципов:

1. Участие: обеспечение инклюзивного, разнообразного, безопасного, независимого и значимого участия гражданского общества в процессе принятия решений, в соответствии с

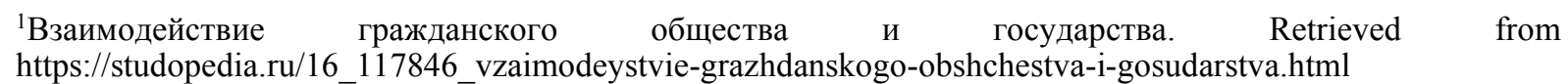


повесткой дня в Области Устойчивого Развития на период до 2030 года и пропаганда инклюзивного, безопасного и значимого участия гражданского общества в межправительственных процессах Организации Объединенных Наций.

2. Защита: Содействие защите субъектов гражданского общества, подвергающихся риску (в том числе от актов запугивания и репрессий за сотрудничество с Организацией Объединенных Наций).

3. Продвижение: активное продвижение открытого гражданского пространства, включая правовые и политические рамки, которые облегчают дебаты онлайн и офлайн, и позволяют гражданскому обществу свободно собираться. ${ }^{1}$

Необходимость активного участия институтов гражданского общества в достижении ЦУР обусловлена тем, что «эффективные возможности гражданского участия в жизни общества содействуют сплоченности общества и открывают людям, в том числе меньшинствам и тем, кто занимает маргинальное положение в обществе, путь, позволяющий им добиться того, чтобы их голос был услышан».

Важно подчеркнуть, что некоммерческий сектор седьмая крупнейшая экономика в мире, идущая сразу за Великобританией и Францией, опережая Италию, Бразилию, Россию, Испанию и Канаду; некоммерческий сектор один из крупнейших работодателей, а также действенный механизм мобилизации общественных ресурсов. ${ }^{3}$ Таким образом, некоммерческий сектор вносит вклад не только в удовлетворение потребностей населения, но и в создание благоприятного делового климата, стабильность экономического развития и политической системы, основанной на принципах демократии, прозрачности и ответственности, что, в свою очередь, немаловажно для достижения ЦУР.

\section{2. Функции и вклад гражданского общества в достижении ЦУР}

В процессе достижения ЦУР гражданскому обществу отводится значимая роль. Как известно, самое успешное партнерство - это партнерство, четко ориентированное на конкретные задачи, где каждый партнер занимается чем-то конкретным. Поэтому важно четко обозначить функции гражданского общества в достижении ЦУР.

Прежде всего, гражданское общество призвано оказывать содействие правительству в достижении ЦУР на национальном уровне путем выдвижения инициатив по реализации ЦУР и их продвижения. Институты гражданского общества должны и могут стать инициаторами существенных социальных преобразований.

Институты гражданского общества могут служить связующим мостом между государством и населением ${ }^{4}$, доводя до сведения государственных органов нужды и потребности общества, трансформируя отзывы населения в социально значимые инициативы. То есть гражданское общество может выполнять роль консультанта правительства в достижении ЦУР. ${ }^{5}$ Странам с переходной экономикой приходится, в частности, нередко полагаться на экспертный потенциал и услуги гражданского общества. ${ }^{6}$ Официальные и неофициальные консультации государств с гражданским обществом способствуют росту взаимопонимания, повышают взаимное доверие и укрепляют потенциал сотрудничества. ${ }^{7}$

\footnotetext{
${ }^{1}$ Руководящая записка ООН по защите и развитию гражданского пространства. - Сент. 2020. - C.3. Retrieved from https://www.ohchr.org/Documents/Issues/CivicSpace/UN_Guidance_Note_Executive_Summary_RU.pdf

2 Доклад Верховного комиссара Организации Объединенных Наций по правам человека. Практические рекомендации для создания и поддержания безопасных и благоприятных условий для деятельности гражданского общества, основанные на передовой практике и извлеченных уроках. 2016. Retrieved from http://undocs.org/ru/A/HRC/32/20

${ }^{3}$ Retrieved from https://pandia.ru/text/79/492/22964.php

${ }^{4}$ Xinya Yan 1, Haiying Lin 2,* and Amelia Clarke. Cross-Sector Social Partnerships for Social Change: The Roles of Non-Governmental Organizations // Sustainability 2018, 10, 558 - P.3. Retrieved from www.mdpi.com/journal/sustainability)

${ }^{5}$ Там же, C. 10.

${ }^{6}$ Доклад Верховного комиссара Организации Объединенных Наций по правам человека. Практические рекомендации для создания и поддержания безопасных и благоприятных условий для деятельности гражданского общества, основанные на передовой практике и извлеченных уроках. 2016. Retrieved from http://undocs.org/ru/A/HRC/32/20

${ }^{7}$ Там же
} 
Институты гражданского общества также вносят вклад достижение ЦУР путем реализации различного рода социально ориентированных проектов ${ }^{1}$

Институты гражданского общества вносят вклад в повышение информированности общества о ЦУР. ${ }^{2}$ К сожалению, некоторые исследования свидетельствуют о низком уровне осведомленности общества о ЦУР. Сегодня не только широкие слои населения, но и многие лица, принимающие решения, имеют весьма смутные представления о том, что такое устойчивое развитие и почему его обеспечение является приоритетом мирового сообщества. Так, опросы показали, что в Европе только 54\% опрашиваемых осведомлены о ЦУР и национальных планах по их достижению, а в африканских странах - только $29 \% .{ }^{3}$ Очень важно, чтобы гражданское общество взяло на себя ответственность по просвещению местных властей, грантодателей, бизнеса и своих коллег о Повестке-2030 и ЦУР.

Гражданское общество играет ключевую роль в мониторинге и обеспечении подотчетности правительств, а также частного сектора. В частности, сегодня государства внедряют практику представления добровольных отчетов о достижении ЦУР. Гражданское общество представляет альтернативные отчеты о достижении ЦУР, благодаря которым можно получить более целостное представление о проблемах в сфере достижения ЦУР.

Одна из ЦУР - ЦУР 17 - закрепляет глобальное партнерство. Институты гражданского института (далее ИГО) служат инструментом для укрепления такого партнерства. Так, например, сегодня действуют коалиции гражданского общества, которые вносят огромный вклад в продвижение идей ЦУР.

Таким образом, институты гражданского общество могут играть роль инициаторов социальных преобразований, консультантов, коммуникаторов, контролеров и инструментов укрепления партнерства как на национальном, так и на глобальном уровне, в процессе достижения ЦУР.

\section{3. Лучшие практики по вовлечению иго в достижение ЦУР}

\section{1. Добровольные национальные обзоры и вовлечение ИГО в их подготовку}

Каждое государство должно представлять на политическом форуме ООН высокого уровня о своей работе над ЦУР хотя бы два раза за 15 лет в виде добровольных национальных обзоров (ДНО) государств, в которых каждая страна рассказывает о своем опыте, успехах и вызовах при реализации Повестки дня в области устойчивого развития до 2030 года (Повестки-2030) и ее 17 целей (ЦУР). ДНО посвящен анализу не только динамики количественных показателей, характеризующих достижение ЦУР, но и качественному анализу мер государственной политики, проектов институтов развития, исследовательских и общественных организаций и бизнеса.

Страны стремятся до 2030 года представить свои обзоры не единожды. Некоторые уже сделали это дважды, например Аргентина, Армения, Бангладеш, Финляндия, Индия, а Того и Бенин - трижды. ${ }^{4}$

Особого внимания заслуживают отчеты ЕC. С 2017 года Евростат публикуют ежегодные отчеты "Sustainable development in the European Union: Monitoring report on progress towards the SDGs in an EU context" (Устойчивое развитие в ЕС: доклад по мониторингу прогресса в достижении ЦУР в контексте ЕС). В этих докладах на основе 100 индикаторов оценивается достигнутый прогресс. ${ }^{5}$

Но, при этом, следует отметить, что даже на уровне ЕС, которое претендует на роль лидера в достижении ЦУР, наблюдается низкий уровень участия гражданского общества в мониторинге ЦУР. ${ }^{6}$ Важно обеспечивать активное участие ИГО в подготовке ДНО.

\footnotetext{
${ }^{1}$ Elisabeth Hege, Damien Demailly(IDDRI). How do NGOs mobilize around the SDGs and what are the ways forward? A French-German comparison. - C.8.

2 The Roles of Civil Society in Localising the Sustainable Development Goals. - ACSC, March, 2016. -P.3. Retrieved from https://www.gppi.net/media/KAS_CSO_2016_Localizing_SDGs.pdf

${ }^{3}$ Elisabeth Hege, Damien Demailly(IDDRI). How do NGOs mobilize around the SDGs and what are the ways forward? A French-German comparison. - C.3.

${ }^{4}$ Добровольные национальные

обзоры государств доступны

на

https://www.ohchr.org/RU/Issues/SDGS/Pages/2020VoluntaryNationalReviews.aspx

5 Time to reach for the moon. Civil society SDG monitoring report. 25 September 2020. - P.17. Retrieved from https://eeb.org/time-to-reach-for-the-moon-the-eu-needs-to-step-up-action-and-lead-the-transformation-to-sustainability/

${ }^{6}$ Там же, C.19.
} 


\section{2. Добровольные гражданские обзоры как форма участия ИГО в мониторинге за выполнением обязательств государствами в рамках ЦУР}

Как показала практика, государственные обзоры не всегда отражают реальное состояние дел в странах. Часто проблемные аспекты опускаются, а в фокусе оказываются только достижения. Поэтому гражданское общество, которое действительно нацелено на достижение ЦУР, начало выпускать параллельные обзоры (Добровольный гражданский обзор, или ДГО). ${ }^{1}$ Эти обзоры не только демонстрируют положительные тренды, но и освещают проблемы развития, которые государство игнорирует или не замечает.

Это независимые доклады гражданского общества, которые также называют «теневыми отчетами» (shadow reports), «отчетами всеобщего внимания» (spotlight reports) или «параллельными отчетами» (parallel reports). Они актуальны, когда организации гражданского общества (ОГО) не были привлечены к подготовке Добровольного национального обзора (ДНО) и считают, что ДНО не отражает реальность и не освещает проблемные аспекты реализации ЦУР в стране. ${ }^{2}$

В 2019 году международные представители гражданского общества потребовали дать Гражданским обзорам более официальный статус на Политическом форуме высокого уровня.

Чаще всего гражданские обзоры также ориентированы на выработку рекомендаций для государства и построение диалога для прогресса по ЦУР. К подготовке альтернативного обзора приглашают представителей гражданского общества со всей страны обеспечило представленность гражданского общества на международных переговорах по Повестке-2030, помогло многим организациям по-новому оценить значимость своей деятельности в контексте ЦУР.

\section{3. Участие ИГО в глобальных и региональных форумах по ЦУР}

ИГО могут внести свой вклад в реализацию Повестки 2030 не только на местном, но и на глобальном уровне. При поддержке региональных комиссий ООН было создано несколько региональных форумов устойчивого развития. Ежегодно весной в Женеве проходит такой форум при поддержке Европейской экономической комиссии ООН (ЕЭК ООН). Также можно отметить наличие региональных форумов по ЦУР - Африканский региональный форум по ЦУР (African Regional Forum for Sustainable Development (ARFSD), Арабский форум по ЦУР (Arab Forum on Sustainable Development) и Азиатско-Тихоокеанский форум по ЦУР (Asia-Pacific Forum for Sustainable Development (APFSD), где также уделяется особое внимание участию гражданского общества.

\section{4. Международные коалиции гражданского общества для реализации ЦУР}

Международные коалиции гражданского общества стараются привлечь как можно больше представителей гражданского общества к реализации ЦУР. Они вовлекают их в удаленную работу над документами, разрабатывают для них учебные материалы, проводят вебинары, формируют добровольные объединения и рабочие группы, в которые могут входить ИГО со всего мира.

- Action for Sustainable Development - всемирная гражданская платформа, цель которой - объединить граждан и гражданское общество и вдохновить их на реализацию Повестки $2030 .^{3}$

- Together2030 - глобальная инициатива, направленная на сбор и распространение знаний о реализации и подотчетности Повестки $2030^{4}$.

- TAP Network (Сеть прозрачности, подотчетности и участия) - сеть организаций гражданского общества, которая работает для обеспечения того, чтобы «открытое, инклюзивное, подотчетное, эффективное управление и мирное общество были в центре Повестки 2030». ${ }^{5}$

- Forus - глобальная сеть национальных платформ НКО и региональных коалиций, «вносящих коллективный вклад в развитие, мир, демократию, устойчивость и справедливость» ${ }^{6}$.

\footnotetext{
${ }^{1} \mathrm{C}$ добровольными гражданскими обзорами можно ознакомиться на сайте международной коалиции «Actions for sustainable development» - объединения более 500 HНО из 22 стран - https://action4sd.org/resources-toolkits/. Ha сайте также можно ознакомиться с докладами, посвященными роли ИГО в достижении ЦУР.

${ }^{2}$ Сайт Коалиции за устойчивое развитие России (КУРС). http://kurs2030.ru/dgo

${ }^{3}$ Более подробная информация об инициативе доступна на официальном сайте www.action4sd.org

${ }^{4}$ Более подробная информация об инициативе доступна на официальном сайте https://www.together2030.org/

${ }^{5}$ Более подробная информация об инициативе доступна на официальном сайте https://tapnetwork2030.org

${ }^{6}$ Более подробная информация об инициативе доступна на официальном сайте http://forus-international.org
} 
- Make Europe Sustainable For All - ежсекторальный проект, осуществляемый 25 партнерами со всей Европы. Его цель - содействовать реализации ЦУР в ЕС ${ }^{1}$.

Таким образом, обзор лучших практик свидетельствует о необходимости вовлечения ИГО на всех уровнях реализации ЦУР -национальном, региональном и глобальном.

\section{5. Молодежные посланники ЦУР}

Еще одной хорошей практикой в достижении ЦУР можно считать опыт РФ, в частности, реализацию программы «Молодежные посланники ЦУР России». Реализация вышеуказанной программы направлена на популяризацию ЦУР среди российской молодежи, информирование о глобальных проблемах и механизмах их решения, а также вовлечение молодых людей в реализацию ЦУР путем участия в общественных мероприятиях. Программа включает проведение ежегодного отбора Молодежных посланников ЦУР России - 17 молодых представителей гражданского общества, которые призваны содействовать в информировании и активизации своих сверстников в решении проблем человечества. Участниками вышеуказанного отбора могут стать молодые лидеры в возрасте от 18 до 30 лет, владеющие навыками общественного лидерства, публичных выступлений, блоггинга, которые через свои общественные инициативы локального или национального уровня вносят вклад в достижение одной ЦУР. ${ }^{2}$ Деятельность Молодёжного посланника почётна и безвозмездна. ${ }^{3}$ Подобная практика особенно значима для активизации молодежи и молодежных ННО.

\section{6. Конкурсы среди ННО по вопросам устойчивого развития}

Для активизации гражданского общества и вовлечения в процессы достижения ЦУР важно в целях поощрения и стимулирования организовывать различного рода конкурса. Так, в Казахстане проводятся Ярмарки социальных идей и проектов «Локальные решения глобальных проблем в интересах устойчивого развития». В рамках Ярмарки для всех желающих работников третьего сектора организуется образовательная программа: вебинары от ведущих экспертов в сфере продвижения НПО и развития социальных стартапов. ${ }^{4}$

\section{развития}

3.7. Другие информационно-просветительские меры по вопросам устойчивого

Для повышения информированности населения о ЦУР и национальных планах важно создавать электронные базы данных о ЦУР, доступные для населения, открывать ресурсные центры и библиотеки по вопросам ЦУР, широко пользоваться потенциалом социальных сетей в данном направлении. В качестве позитивного опыта можно указать проведении недель ЦУР. Можно организовать недели ЦУР как на уровне страны, так в регионах, а также в рамках учебных заведений, включая школы и университеты.

\section{4. Проблемы касательно участия иго в достижении ЦУР}

Несмотря на принимаемые усилия, во многих исследованиях о роли гражданского общества в достижении ЦУР отмечается отсутствие диалога между правительством и ИГО по вопросам достижения ЦУР, слабая вовлеченность ИГО в процессы разработки национальных планов развития по достижению ЦУР, недостаточный уровень финансирования их деятельности, отсутствие активного участия в мониторинге выполнения обязательств государств в рамках ЦУР.

\section{5. Участие гражданского общества в достижении ЦУР в Узбекистане}

В Узбекистане приняты ряд мер по достижению ЦУР. Принято Постановление Кабинета Министров Республики Узбекистан от 20 октября 2018 года № 841 о национальных целях и задачах в области устойчивого развития на период до 2030г. ${ }^{5}$

В соответствии с Дорожной картой по организации имплементации Национальных целей и задач в области устойчивого развития на период до 2030 года, утвержденной данным Постановлением, создан веб-сайта Национальных ЦУР. ${ }^{6}$ Данный веб-сайт предназначен для обеспечения централизованного доступа к информационным ресурсам, которые позволят

\footnotetext{
${ }^{1}$ Более подробная информация об инициативе доступна на официальном сайте https:/makeeuropesustainableforall.org/

${ }^{2}$ Retrieved from https://pravitelstvo.kbr.ru/oigv/uvigodn/index.php?ELEMENT_ID=23666

3 Официальный вебсайт Национального совета молодежных и детских объединений России http://youthrussia.ru/sustainabledevelopment

${ }^{4}$ Информация взята c https://fnn.kz/ru/news/405

5 Текст Постановления доступен на https://lex.uz/ru/docs/4013358

${ }^{6}$ С докладом Узбекистана можно ознакомиться на https://www.ohchr.org/Documents/Issues/SDGS/2020VN RCountries/UZBEKISTAN_Russian.pdf
} 
отслеживать выполнение принятых Правительством Республики Узбекистан целей и задач устойчивого развития на основе международно-принятых показателей ООН.

Создана Парламентская комиссия по контролю за реализацией Национальных целей и задач в области устойчивого развития Республики Узбекистан на период до 2030г. В 2020 году Узбекистан представил Добровольный национальный обзор на Политическом форуме высокого уровня по устойчивому развитию в 2020 году. ${ }^{1}$

Принимаются меры по вовлечению гражданского общества в процессы достижения ЦУР. В 2021 году создано ННО «Центр устойчивого развития». С учетом лучших практик, следует принять следующие меры в Узбекистане:

- провести опросы среди населения о ЦУР для выявления уровня осведомленности населения о национальных стратегиях и планах развития по достижению ЦУР;

- принимать меры по повышению осведомленности о ЦУР путем создания ресурсных центров и библиотек по вопросам достижения ЦУР и активного использования социальных сетей, организации недель ЦУР в учебных заведениях или на республиканском уровне;

- создать коалицию ННО по достижению ЦУР для проведения исследований, информационно-просветительских мероприятий, реализации проектов, направленных на решение вопросов устойчивого развития;

- организовать национальные консультации по достижению ЦУР с широким участием ИГО;

- внедрить практику назначения молодежных посланников ЦУР;

- обеспечить подготовку добровольных альтернативных докладов (или добровольных гражданских обзоров) ННО о достижении ЦУР;

- активно изучать опыт зарубежных стран в обеспечении активного участия ИГО в достижение ЦУР²;

- инициировать проведение региональных форумов по вопросам достижения ЦУР (можно в рамках региональных организаций - СНГ, ШОС или среди центральнозиатских стран).

В заключение отметим, что сильное и активное гражданского общество - один из признаков высокого уровня развития государства. Для укрепления гражданского общества важно создать соответствующую правовую основу и благоприятную среду для его развития. Следует обеспечивать вовлечение институтов гражданского общества во все этапы реализации ЦУР - от разработки национальных планов действий по достижению ЦУР до отчетности. При этом, важно укреплять взаимодействие не только между государством и институтами гражданского общества, но взаимодействие между самими институтами гражданского общества, в том числе путем создания их коалиций.

\section{ЛИТЕРАТУРА}

1. Взаимодействие гражданского общества и государства. Retrieved from https://studopedia.ru/16_117846_vzaimodeystvie-grazhdanskogo-obshchestva-i-gosudarstva.html

2. Доклад Верховного комиссара Организации Объединенных Наций по правам человека. Практические рекомендации для создания и поддержания безопасных и благоприятных условий для деятельности гражданского общества, основанные на передовой практике и извлеченных уроках. 2016. Retrieved from http://undocs.org/ru/A/HRC/32/20

3. Добровольные национальные обзоры государств о выполнении ЦУР. Retrieved from https://www.ohchr.org/RU/Issues/SDGS/Pages/2020VoluntaryNationalReviews.aspx

4. Добровольные гражданские обзоры о выполнении ЦУР. Retrieved from https://action4sd.org/resources-toolkits/

5. Добровольный национальный обзор Узбекистана (https://www.ohchr.org/Documents/Issues/SDGS/2020VNRCountries/UZBEKISTAN_Russian.pdf)

6. Руководящая записка ООН по защите и развитию гражданского пространства. - Сент. 2020. - C.3. Retrieved from https://www.ohchr.org/Documents/Issues/CivicSpace/UN_Guidance_Note_Executive_Summary_RU.pdf

7. Elisabeth Hege, Damien Demailly(IDDRI). How do NGOs mobilize around the SDGs and what are the ways forward? A French-German comparison. - C.8.

8. The Roles of Civil Society in Localising the Sustainable Development Goals. - ACSC, March, 2016. -P.3. Retrieved from https://www.gppi.net/media/KAS_CSO_2016_Localizing_SDGs.pdf

\footnotetext{
${ }^{1}$ Веб-сайт Национальных ЦУР в Узбекистане. http://nsdg.stat.uz/

2 По итогам 2019 года лидерами в достижении ЦУР являются следующие страны: Дания $\left(85,2^{*}\right)$, Швеция $(85,0)$, Финляндия $(82,8)$, Франция $(81,5)$, Австрия $(81,1)$, Германия $(81,1)$, Чехия $(80,7)$, Норвегия $(80,7)$. Retrieved from https:/terra-ecology.ru/ustojchivoe-razvitie-kak-strany-boryutsya-za-budushhee-planety/
} 
9. Time to reach for the moon. Civil society SDG monitoring report. 25 September 2020. - C.17. Retrieved from https://eeb.org/time-to-reach-for-the-moon-the-eu-needs-to-step-up-action-and-lead-thetransformation-to-sustainability/

10. Xinya Yan, Haiying Lin and Amelia Clarke. Cross-Sector Social Partnerships for Social Change: The Roles of Non-Governmental Organizations // Sustainability 2018, 10, 558 -P.3. Retrieved from www.mdpi.com/journal/sustainability)

11. Сайт Коалиции за устойчивое развитие России (КУРС). http://kurs2030.ru/dgo

12. Официальный вебсайт Национального совета молодежных и детских объединений России http://youthrussia.ru/sustainabledevelopment

13. Retrieved from https://fnn.kz/ru/news/405

14. Постановление Кабинета Министров Узбекистан о национальных целях и задачах в области устойчивого развития на период до 2030 г. (https://lex.uz/ru/docs/4013358)

15. Веб-сайт Национальных ЦУР в Узбекистане. Retrieved from http://nsdg.stat.uz/

16. Retrieved from https://terra-ecology.ru/ustojchivoe-razvitie-kak-strany-boryutsya-za-budushhee-planety/

17. Retrieved from https://pandia.ru/text/79/492/22964.php 